\title{
LA CRISIS DEL LENGUAJE COMUNICATIVO Y EL RECURSO DE LA FANTASÍA
}

\author{
Leopoldo DE LA RUBIA DE PRADO
}

La literatura, - y el arte, en general-, han recurrido a distintos modos de expresión o códigos expresivos a lo largo de la historia, aunque también es cierto que ya en la Antigüedad clásica se encuentran gran parte de los recursos de los que se hizo uso durante siglos. A nadie escapa, por ejemplo, que la Poética de Aristóteles sigue siendo un pilar fundamental sobre el que se asienta un modo de concebir la creación artística aún hoy. En el presente artículo voy a ocuparme del modo de concebir la creación literaria desde la crisis del Realismo decimonónico hasta la literatura de entre guerras, fundamentalmente en la obra de algunos autores checos como Franz Kafka, Alfred Kubín o Karel Capek, que pusieron un especial énfasis en el uso de la fantasía ${ }^{1}$ al servicio de la realidad. En este sentido, este artículo bien podría versar sobre otros tres geniales autores polacos de entre guerras como fueron Bruno Schulz, Witold Gombrowicz o Stanislaw Ignacy Witkiewicz que comparten con los checos un modo muy particular y, en ciertos aspectos, análogo de entender la creación artística

Entre finales del siglo XIX y principios del siglo XX surgen las primeras vanguardias artísticas europeas, las cuales suponen toda una revolución en los modos de expresión y en la exploración de la realidad. Reaccionan frente a la estética del Realismo tratando de enfatizar cuestiones formales, montaje, fragmento, desfiguración, etc. Ellos dirían en un sentido no convencional que su

1 Utilizo este concepto, aunque, en ocasiones, con él me refiero a lo fantástico, lo sobrenatural, lo prodigioso o lo maravilloso, y no sólo a la fantasía del autor. 
manera de ver el mundo es una exploración de la realidad que plasma dimensiones de la misma que escapan al Realismo decimonónico. El Impresionismo, que es una de las últimas formas de realismo no comprometido, también supone una espectacular proyección del modo de percepción del artista que ve el mundo de una manera muy particular, cercano al propugnado por las leyes de la Gestalt. Son las sucesivas vanguardias como el Fauvismo, el Expresionismo, el Cubismo y el Cuboexpresionismo checo, el Futurismo, el Dadaísmo, el Surrealismo y la abstracción, las que se convertirán en una bocanada de aire fresco dentro del maltrecho Realismo y del Naturalismo decimonónico que parecían agotados. Esta es una época en que entra en crisis el lenguaje referencial o comunicativo produciéndose una revolución lingüística en el plano teórico que afectará al campo de las artes. Sin embargo, la crisis afectará no sólo a estos campos, sino también al propio concepto de realidad que en el Expresionismo y en la mayoría de las vanguardias aparece distorsionada con el fin de explorarla yendo más allá de las meras apariencias. A finales del siglo XIX aparecen los primeros movimientos artísticos que darían lugar a las posteriores vanguardias como reacción a un Realismo que durante gran parte del siglo había dado buenos frutos, pero que, sin embargo, aparecía ahora gastado e incapaz con sus recursos expresivos de profundizar en una realidad que se le hacía esquiva. En este sentido Bruno Schulz escribe: «Con el paso del tiempo, la palabra se endurece, coagula, deja de ser el conducto de nuevos significados" ${ }^{2}$.

La realidad política del Imperio Austro- Húngaro y Alemán, el maquinismo, la alienación y el sufrimiento al que se ve avocada la sociedad centroeuropea, dominada hasta entonces por el modelo de las ciencias naturales que, a juicio de Edmund Husserl, promueve un modelo de objetividad que se extiende a todos los ámbitos de la sociedad y que, como sabemos, dio tan pobres resultados, tiene una consecuencia inevitable: es necesario intensificar el concepto de realidad al cual se le añadirá en aquella época el elemento utópico del siglo XX. De todo ello surge una desconfianza en el acto mismo de la comunicación que, a su vez, cae bajo esa misma presunta objetividad positivista que tiene su colofón en afirmaciones tan radicales como incendiarias en alguno de los neopositivistas que afirman que los libros de metafísica deberían ir todos a la hoguera. La comunicación nos presenta un abismo entre lengua y significado; el lugar donde se esconde el significado de las palabras no está nada claro,

2 Bruno Schulz, Obra Completa, Siruela, Madrid, 1998, p. 328. 
la disputa entre esencialistas y nominalistas sigue en pie; la verdad que parecía un concepto bien asentado deja de estarlo. Todos estos conceptos ${ }^{3}$, pilares indiscutibles hasta entonces, se convierten en instancias que se tambalean, acaso noqueadas y con pocas esperanzas de reafirmación o reconsolidación. Pero tras estas primeras vanguardias artísticas y la ruptura con el Realismo (que no con la realidad), es decir, ruptura con el realismo ingenuo y con el Naturalismo, se encuentran las ideas de Nietzsche (1844-1900), Freud (18561939), Husserl (1859-1938) o Wittgenstein (1889-1951), entre otros.

En su obra Sobre verdad y mentira en sentido extramoral, Friedrich Nietzsche, critica el lenguaje y la idea de verdad, pues ésta es una mentira colectiva. Garrido comenta en el Prólogo: «Son sólo razones o necesidades de utilidad social $[. .$.$] las que dan lugar a la codificación social del lenguaje y a que$ la sociedad premie la verdad y penalice la mentira» ${ }^{4}$. La verdad sería, pues, convencional. El hombre ansía, dice Nietzsche, las consecuencias agradables de la verdad, es decir, las que mantienen la vida, y es indiferente frente a las verdades susceptibles de efectos perjudiciales o destructivos. Nietzsche se pregunta con clara ironía si concuerdan las designaciones y las cosas (lenguaje referencial) y si es el lenguaje la expresión adecuada de todas las realidades. En unas palabras profundamente irónicas expresa lo siguiente: "Dividimos las cosas en géneros, caracterizamos al árbol como masculino y a la planta como femenino: iqué extrapolación tan arbitraria! ¡A qué altura volamos por encima del canon de la certeza! [...] con las palabras jamás se llega a la verdad ni a una expresión adecuada pues, en caso contrario, no habría tantos lenguajes" 5 .

Este planteamiento nietzscheano acerca de la verdad y del lenguaje, de su construcción convencional y la virtualidad que lo caracteriza fue asumido por

3 Entre estos conceptos, "pilares indiscutibles" se encuentran "sujeto" y "conciencia"; sin embargo, en la obra de Paul Ricoeur Hermenéutica y psicoanálisis (1965) acuña la expresión de "filosofía de la sospecha" refiriéndose a Marx, Freud y Nietzsche, "los que arrancan las máscaras", los cuales someten a crítica la noción tradicional de "sujeto" y "conciencia". Nietzsche afirma el origen social de la conciencia y la necesidad de desenmascarar cuanto se oculta tras ella. Su tarea va a consistir, por tanto, en una crítica a la moral. Para Marx la conciencia constituye un mero reflejo de las relaciones económicas de producción, mientras que para Freud la conciencia es un producto del inconsciente.

4 GARRIDO, M., "Prólogo». Friedrich Nietzsche. Sobre verdad y mentira en sentido extramorah Tecnos, Madrid, 1996, p. 10.

5 Friedrich Nietzsche. Sobre verdad y mentira en sentido extramoral Tecnos, Madrid, 1996, p. 22. 
las vanguardias, que encontraron en teorías como el psicoanálisis otro pilar del cual obtuvieron deliciosos frutos. La referencialidad del lenguaje quedó, una vez más, en entredicho toda vez que además del contenido de la palabra, de lo dicho, está el contenido de lo oculto, de lo no dicho, de lo inconsciente. En este caso la brecha se hace aún mayor puesto que desde la teorización sobre el inconsciente por parte de Freud, sabemos que lo dicho, la palabra, el pensamiento o lo que creemos reflejo y expresión del pensamiento con el significado que dicha expresión pueda tener no es siempre el que creemos. Lo oculto puede ser tan revelador o más que lo explícito. La expresión de nuestro pensamiento y el supuesto significado del mismo no siempre coinciden. Este extremo ha sido descubierto por el psicoanálisis; así, cuando alguien, un paciente, un artista o quienquiera que sea expresa algo puede estar diciendo todo lo contrario, voluntariamente o no. Por otro lado, tras lo dicho se pueden esconder prejuicios, lugares comunes o una visión del mundo que revele, al menos, paradojas y hasta contradicciones difíciles de detectar sin un riguroso análisis; de ahí que la referencialidad del lenguaje quede otra vez bajo sospecha. Pero lo más curioso es, cómo el mismo Sigmund Freud comenta, que su método estaba más cerca de la superstición que de la ciencia médica: «Para mi gran asombro, descubrí un día que no era la concepción médica del sueño, sino la popular, medio arraigada aún en la superstición, la más cercana a la verdad" ${ }^{6}$. En este sentido tanto Freud, que encuentra en la concepción del sueño arraigado en la superstición su método; Nietzsche, que entiende que la vieja verdad que, además de ser convencional, se acerca a su final o el mismo Kafka, que en su obra revisa los viejos mitos otorgándoles un nuevo sentido ( $\mathrm{El}$ silencio de las sirenas", «El buitre») y creando mitos nuevos, perfilan una situación en la que el viejo lenguaje y la verdad de siempre no son más que imagen virtual de la realidad.

Por si el paisaje semántico del lenguaje habitual no estuviera en plena crisis, Wittgenstein viene a decirnos que el significado de las palabras está en el uso que de ellas hagamos ${ }^{7}$, con lo que desaparece toda esencialidad de la palabra entendida ésta como una relación necesaria entre significante y significa-

6 FREUD, S. La interpretación de los sueños, Planeta Agostini, Barcelona, 1992, p. 9.

7 Con esta idea defendida por Ludwig Wittgenstein, nos referimos al llamado «segundo Wittgenstein" que es el Wittgenstein de las Investigaciones filosóficas. En oposición al "segundo Wittgensteín" (aunque autores que opinan que no existe discontinuidad entre ambos) el "primer Wittgenstein" es el Wittgenstein del Tractatus. 
do. Del convencionalismo de la verdad al pragmatismo semántico pasando por los significados ocultos en el inconsciente opuesto muchas veces a lo dicho. Tal es el panorama que entre finales del XIX y principios del XX queda expuesto para que las vanguardias y la nueva literatura se replanteen si las cosas deben seguir como hasta entonces.

En este horizonte marcado por la desconfianza en instancias que se creían estables nacen las nuevas vanguardias, pero la ruptura con movimientos artísticos anteriores no es tan radical como podría parecer. Al Realismo no se le opone ningún movimiento que pretenda romper con él ni con el lenguaje, pues es todo lo que tenemos. Todo lo contrario. El objetivo es reactivar el concepto de realidad, reanimarlo, revitalizarlo. Ese lenguaje, erosionado por el uso, era necesario revigorizarlo incrementando su dinamicidad (de ahí la gran utilización de los distintos tipos de metáfora por parte de los expresionistas). Nuevos juegos del lenguaje, la utilización de nuevos códigos lingüísticos y expresivos, así como la transformación de viejos mitos y el rescate de lo olvidado, lo primitivo; el propio signo que llama la atención sobre sí mismo en un ejercicio de autorreflexividad y otros mecanismos condenados al ostracismo por el paradigma positivista vuelven a cobrar vigencia al servicio de la realidad. Como sostiene García Leal «el lenguaje poético se mantiene en conflicto con el lenguaje común. El poeta pugna con las palabras, y esa pugna se resuelve en una deformación de la sintaxis del lenguaje ordinario, en la de construcción y nueva articulación de los signos lingüísticos: le es necesario violar las reglas del lenguaje común para que las palabras adquieran una nueva dimensión expresiva. De ese modo, aparecen nuevos ritmos, nuevos tonos y cadencias, nuevas asociaciones de palabras, en definitiva, un nuevo orden compositivo al que queda vinculada una nueva expresividad ${ }^{8}$. Estos elementos de una nueva expresividad se hacen patentes en todas las manifestaciones artísticas tales como la poesía, la literatura o la músi$\mathrm{Ca}^{9}$. Este es, por tanto, el modo adecuado de entender las formas de realismo

8 Garcla Leal, J., Arte y conocimiento, Universidad de Granada y Diputación, Granada, 1995, p. 42.

9 Es paradigmática en la búsqueda de una nueva expresividad, de nuevos lenguajes y códigos expresivos en el campo de la música la obra de Arnold Schönberg. Este autor, discípulo de Mahler, comenzará en la línea postromántica con su obra Gurrelieder, pero inmediatamente va a evolucionar creando un lenguaje totalmente nuevo en la línea del Expresionismo. Schönberg termina totalmente con la tonalidad; su "atonalismo" consiste en olvidarse de las leyes de la tonalidad. Del atonalismo pasará en 1908 -época del Expresionismo- a lo que él llamó "Composición con doce sonidos sin relación entre ellos", es decir, al "dodecafonismo" o "musi- 
del siglo XX entre las cuales hallamos la obra misma de Franz Kafka y el mundo propio que el autor checo creó.

La fantasía como modo de exploración de la realidad. La literatura checa y A. Kubín

Las vanguardias artísticas hasta mediados del siglo XX fueron especialmente prolíficas en el uso de medios de expresión no realistas con el paradójico objetivo de captar ese aspecto cuyo conocimiento se hace esquivo que no es otro que la realidad. Junto a los distintos modos de expresión no realista propios del Cubismo, el Expresionismo, el Cuboexpresionismo checo o el expresionismo abstracto, la fantasía reaparece como medio privilegiado de acceso a la realidad, preferentemente en la literatura checa del primer tercio del siglo XX, cuyos ejemplos arquetípicos se encuentran en obras como La transformacion (1912) de Franz Kafka, R.U.R. (1920) o La guerra de las salamandras (1936) de Karel Capek o La otra parte (1909) de Alfred Kubín. Con posterioridad, el también autor checo Pavel Kohout en su obra Cabeza abajo (1970) continuaría la senda de sus célebres compatriotas.

Las distintas vanguardias artísticas hicieron uso, pues, de nuevos códigos expresivos, pero es preciso destacar el papel de la fantasía como modo de acceso - privilegiado- a la realidad. La literatura, por ejemplo, pero también otras manifestaciones artísticas, encontraron en la fantasía un eficaz instrumento capaz de producir nuevos cortocircuitos en el plano semántico generando así nuevos significados distintos al meramente referencial propio del naturalismo huero y agotado decimonónico del cual ya los grandes maestros de la literatura eslava como Gógol, Tolstoi o Dostoievski comenzaron a distanciarse. La fantasía proporciona, por lo demás, al texto el carácter de pluridiscursividad y nuevas claves hermenéuticas.

Numerosos autores checos - $y$ del mundo eslavo en general- hicieron uso frecuentemente del recurso a la fantasía, sin embargo, he de insistir en que ese recurso no supuso escapismo alguno, aspecto éste asociado a la fantasía. En

ca serial», una música de claro carácter melódico, no armónico que por sus características suena extraña. El dodecafonismo elimina la jerarquía del valor tonal y considera los doce tonos iguales: siete notas más cinco semitonos. 
este sentido Franz Kafka, cuya fantasía parece no tener límites, debe ser considerado como un autor realista a pesar de que todavía a mediados del pasado siglo XX un importante autor como es $\mathrm{G}$. Lukács lo ponía en duda.

La literatura checa en el periodo inmediatamente anterior a la primera gran guerra, pero también la literatura de entre guerras está caracterizada por los siguientes aspectos ${ }^{10}$ :

- Praga como musa, como motivo literario y como escenario de gran parte de las historias narradas por estos escritores.

- Un trasfondo político y social. Una constante preocupación por los problemas de la sociedad que los rodea. Es, por tanto, una literatura comprometida, aunque con diferentes grados de compromiso.

- Es una literatura con un marcado carácter filosófico y humanista, aunque caracterizada en ocasiones por un cierto escepticismo. En la obra de los autores checos hay una profunda reflexión en torno a cuestiones enraizadas en lo más profundo del ser humano, en cuestiones existenciales y, a la vez, -como es el caso de Karel wapek-, por un culto a lo cotidiano que consigue ir más allá de lo aparente rayando en lo fantástico.

- La utilización de la fantasía al servicio de la realidad

- La literatura checa hace gala de ser una literatura en la que no falta un finísimo sentido del humor, donde, por cierto, no está ausente la crítica ni la sátira.

10 Con ello quiero llamar la atención acerca de autores checos o nacidos en Bohemia y Moravia que escribieron en alemán (por ejemplo Hermann Ungar o Leo Perutz), pero que, a mi juicio, deben de ser considerados como formando parte de una literatura hecha en el seno de una cultura tan plural y abigarrada como la checa, entonces parte del Imperio Austro- Húngaro. En este sentido, existe una cierta controversia en relación al carácter checo de Kafka que, como es sabido, escribió su obra en alemán, pero es clarificador recordar algunas de sus ideas respecto al alemán y a los alemanes. En su diario el 24 de octubre de 1911 escribe: "Ayer se me ocurrió que no había amado siempre a mi madre como se merecía y como podía amarla, por el simple hecho de que me lo impedía la lengua alemana. La madre judía no es una Mutter, la denominación de Mutter la convierte en algo ligeramente cómico (raro)" (Diario 73). En otro lugar le expresa a su amigo Gustav Janouch lo siguiente sobre los alemanes: "Los alemanes se niegan a reconocer, comprender y leer. Sólo quieren poseer y gobernar, y para semejante objetivo la comprensión suele ser sólo un obstáculo. Resulta mucho más fácil oprimir al prójimo cuando no se le conoce. Así se evitan posibles remordimientos de conciencia" (JaNOUCH, Conversaciones con Kafka 203). 
Pero, ¿qué quiere decir que la fantasía sea utilizada por diversos autores checos al servicio de la realidad?, ¿Es acaso esto posible? ¿Se puede entonces hablar de autores realistas y no de autores de literatura fantástica?

Intentaré responder a todos estos interrogantes, aunque he de señalar que la hipótesis central que propongo tras mi lectura de numerosos autores checos es que ia fantasia constituye una forma de acceso privilegiado a la realidad.

Es evidente que la fantasía se halla a la base de la obra de Franz Kafka. La frase de Kafka "la realidad auténtica es siempre irreal" ${ }^{11}$ es merecedora, por tanto, de ser analizada porque refleja la fórmula técnico- literaria que Kafka utilizaría en gran parte de su obra: la fantasía como recurso literario capaz de adentrarse y permitir a la realidad mostrarse. «La realidad auténtica es siempre irreal" parece advertirnos de que todo intento por captar lo real o su más íntimo sentido desde la realidad misma está condenado al fracaso puesto que la realidad es con frecuencia inaprehensible e inescrutable. Nos situamos en el plano de lo real, pero no podemos captar la realidad en toda su amplitud ni comprenderla definitivamente. Miramos a nuestro alrededor y vemos los entes, las cosas y hasta creemos ver al ser humano. Pero la realidad es muy distinta puesto que de nuestros congéneres no vemos más que su aspecto físico y aquello que de su espíritu se refleja en sus rostros y sus acciones. No estamos capacitados para ver aquello que realmente vale la pena o que es, ciertamente, relevante; no vemos la amistad, el amor, la comprensión, la virtud, el genio ni comprendemos muy bien el mecanismo que nos diferencia del resto de los seres vivos: nuestra capacidad de simbolización, no podemos ver, en fin, lo espiritual. Hay quien se conforma con tener ese gran instrumento que es la ciencia - y su hija, la técnica- como respuesta a los interrogantes humanos, y es normal, el positivismo se ha convertido en una nueva religión y en privilegiada visión del mundo, pero la ciencia, no lo olvidemos, no es sino una forma más de acceso a la realidad, a la realidad física, no al resto. La realidad se nos escapa y nosotros, ingenuos, creemos comprenderla. Con razón Kafka, hojeando un libro de dibujos de George Gras, concretamente el del hombre gordo con sombrero de copa sentado sobre el dinero de los pobres (El rostro de la clase dominante: ;Ajustaremos cuentas.), dijo:

11 Janouch, G., Conversaciones con Kafka, Destino, Barcelona, 1997, p. 261. 
«Esta es la vieja visión del capital [...] Es correcto e incorrecto a la vez. Sólo es correcto en un sentido, aunque no lo es en la medida en que proclama una visión parcial como si fuera completa. El hombre gordo con el sombrero de copa persigue a los pobres: eso es correcto. Pero el hombre gordo es el capitalismo, y eso ya no es tan correcto. El hombre gordo domina al hombre pobre dentro del marco de un sistema determinado, pero él no es el sistema. Ni siquiera lo domina. Al contrario: el hombre gordo también lleva cadenas que no están representadas en el dibujo. El dibujo es incompleto, por eso no es bueno. El capitalismo es un sistema de dependencias que van de dentro a fuera, de fuera a dentro, de arriba abajo y de abajo arriba. Todo depende de todo, todo está atado. El capitalismo es un estado del mundo y del alma» ${ }^{12}$.

Aprehender la realidad pertenecería, paradójicamente, al campo de la ficción, acaso de la ciencia ficción. La ficción, la fantasía e, incluso, la fantasmagoría (recordemos La otra parte de Kubin como ejemplo de fantasmagoría), se convertirían en uno de los instrumentos más eficaces para la comprensión, siempre parcial, de la realidad. La frontera entre realidad y ficción ${ }^{13}$ jamás se nos presentará diáfana y sí difícil de delimitar. Hoy menos que nunca tras la lectura de las obras de H. G. Wells (La guerra de los mundos), G. Orwell (1984), A. Huxley (Un mundo feliz), J. Verne (Viaje a la luna, 20,000 leguas de viaje submarino) o I. Asimov. Y ambas, realidad y fantasía, se convierten en instrumentos de comprensión mutua. La realidad no puede ser comprendida sólo mirando a nuestro alrededor, y la fantasía, cuyo anclaje se encuentra en la realidad y en la realidad de nuestra imaginación, no sólo desde ella misma. En este sentido, la realidad es difícilmente expresable simplemente con medios realistas, siendo imprescindible ampliar los modos de expresión y representación e incluyendo entre ellos la fantasía.

A nadie escapará que, como escribe García Leal, "la historia del arte, al menos hasta épocas recientes, es la historia del realismo. O lo que es igual, la historia de los distintos modos de entender el realismo" ${ }^{14}$. Pero, ¿Qué es el Realismo ${ }^{15}$ ? Es «un movimiento literario surgido a finales del siglo XIX, junto

12 JanOUCH, G., Conversaciones con Kafka, Destino, Barcelona, 1997, p. 260.

13 Prácticamente cualquier obra literaria es una obra de ficción. Me refiero, pues, en esta ocasión a ficción como plano distinto al de la realidad.

14 JOSE. GARCIA LEAL, "Del realismo al hiperrealismo».

15 Obsérvese la diferencia entre realismo (sentido amplio) y Realismo (movimiento literario). 
con el auge de la burguesía, como reacción ante los excesos del Romanticismo. Se basa en una observación rigurosa de la realidad, por lo que recurre a la descripción minuciosa de ambientes y personajes y a la reproducción del habla coloquial. Se apoya en la filosofía positivista, que se basa en los hechos observables y medibles y que se opone a la idealista en la que se sustentaba el Romanticismo" ${ }^{16}$. Lógicamente, ésta no es más que una definición entre los centenares de ellas que podríamos aportar. El Realismo, prosigue Reyzábal, "presenta rasgos propios y diferenciales con otros movimientos: rechazo de lo puramente sentimental, de lo fantástico y lo maravilloso, así como del regreso nostálgico al pasado, etcm. Está claro que si todo el realismo tuviera que ser subsumido bajo esta definición (u otras similares) siendo excluidos tanto la fantasía como lo maravilloso difícilmente podríamos afirmar el realismo, o si se prefiere, la lectura realista de muchos de los autores como pueden ser Franz Kafka, Alfred Kubin, Karel rapek o Pavel Kohout.

El mismo Karel "apek, etiquetado como escritor de ciencia- ficción, fue el autor de la obra de anticipación escrita en 1920 R.U.R. (Robots Universales Rossum) e inventor del término "robot» ${ }^{17}$. Capek concibe la literatura como vehículo idóneo para expresar sus ideas filosóficas, que expuso a través de originales utopías y visiones satíricas del mundo futuro como R.U.R., donde los robots acaban extinguiendo a sus antiguos amos, los humanos. Efectivamente se trataba de una obra de ciencia ficción, ficción que, a la postre, amenaza desde hace tiempo con convertirse en realidad. Sus novelas La fábrica de lo absoluto, El asunto Makropulos (1922) y Krakatit (1924) advierten, a su vez, sobre los peligros de las modernas sociedades industriales, y propugnan la felicidad humana a través de los placeres sencillos de la vidas. En La guerra de las salamandras, a mi juicio, su obra maestra, el autor se pregunta si en el caso de que una especie animal llegara al mismo grado de desarrollo del hombre, cometería idénticos errores y se dirigiría conscientemente a su autodestrucción. Capek parte del hallazgo (tan fantástico como podría ser la transformación de Gregorio Samsa en insecto) de una nueva raza de seres inteligentes en la Tierra, capaces de progresar con la ayuda del hombre. Sin embargo, el carácter interesado y contradictorio de esta ayuda acabará por destruir toda posibilidad de entendimiento.

16 ReYzABal, M.V., Diccionario de términos literarios, II, Acento, Madrid, 1998, p. 39.

17 Del checo "robota" que significa "trabajo físico». 
La elevadísima tasa de natalidad de las salamandras se convierte no ya en una amenaza, sino en una nueva situación mundial que no permite la convivencia de las dos especies: la humana y la, digamos, "salamandril»; alguien sobra y ese alguien es el hombre, pues las salamandras necesitan ir minando la parte del globo ocupada por tierra para tener más espacio donde desarrollarse en su vida anfibia. Ahora es el hombre quien ha de trabajar para las salamandras, al contrario que a lo largo de la obra; y debe trabajar en la destrucción de su propio hábitat, en la destrucción de nuestro mundo. Capek, al final de la obra, en una especie de desdoblamiento, en un diálogo consigo mismo, se plantea "salvar» a la humanidad ${ }^{18}$, pero se responde que una solución artificial es algo demasiado barato "iTiene que arreglar siempre la Naturaleza lo que estropea la gente?». Mientras las salamandras dinamitan las costas para gozar de más espacio, Capek es consciente de que es el mismo hombre el que sigue proporcionando los explosivos y las taladradoras a las salamandras; es el hombre el que trabaja febrilmente en los laboratorios, a fin de encontrar materias y maquinarias más eficaces para barrer el mundo; es el hombre el que presta a las salamandras ( Mundo. Toda esta temática resulta para el hombre del siglo XXI ser de lo más realista; da la sensación de haber captado a través de lo fantástico, a través de esas prodigiosas salamandras el espíritu de una realidad que va más allá de la mera fantasía del autor. Las obras de Karel Capek son, por tanto, de un atrevido contenido crítico y advierten de los peligros de una sociedad obsesionada por la producción y el consumo. En su obra se descubren preocupaciones éticas y sociales derivadas de una situación histórica plagada de amenazas, de ahí que hayamos de insistir en la vigencia de este autor checo y en el contenido realista de su obra.Afortunadamente, como sugiere García Leal, existe una gran diversidad de realismos $y$, a nuestro juicio, existen diversos modos de acceso a la realidad: a través de la mística; a través de la fantasía e, incluso, a través de la descripción al detalle de lo que aparece o, simplemente, se ve y que en otras épocas algunos osaron llamarle auténtica "realidad».

En este debate acerca del realismo cabe afirmar que no parece que haya una Realidad a la espera de ser captada por una especie de "ojo infalible» capaz de captar la realidad en su totalidad. Nos contentaremos, por tanto, con intentar describir algunos de los medios de acceso que posibilitan aprehender la reali-

18 Como ocurre en La guerra de los mundos, es decir, con una epidemia, por ejemplo. 
dad o alguna parcela de ella a través de medios no realistas como la fantasía (en sentido amplio). En otras palabras, creo que la realidad puede ser explorada desde formas no realistas de expresión y, especialmente, a través de la fantasía y el ejercicio de la imaginación.

De todos es conocido el Guernika de Picasso. En esta obra donde el universal pintor andaluz empleó un modo no realista de expresión, acaso rayano en lo fantástico, plasmó con gran realismo e intensidad el horror de una guerra. Cualquier otro intento de plasmar el significado, el sin sentido o la atrocidad de una guerra tras el punto de inflexión que supone el Guernika no supondría más que un pobre, y hasta torpe- intento. ¿Y es Picasso, el más famoso de los pintores cubistas, un representante del realismo?, o mejor, ¿Es Picasso un realista? La cuestión es que existe una interpretación correcta en clave realista que va más allá de lo aparente. En este sentido, tanto el modo de expresión como el significado (o significados) de la obra trasciende el plano de la pura referencialidad del signo, de lo expresado superficialmente.

Veamos una definición considerada rigurosa de fantasía que nos proporcione algunos elementos de juicio más allá de lo que, intuitivamente, todos sabemos. La fantasía es la facultad de representarse cosas que no existen en la realidad. En general, afirma Konrad Lotter, «la fantasía se encuentra siempre ahí donde se deben solucionar nuevos problemas desde premisas inusuales, tanto en la cotidianidad como en la política, en las ciencias o en la técnica" ${ }^{19}$. Afortunadamente, con esta puntualización es posible otorgarle a la fantasía un papel de gran relevancia en todos los ámbitos de la creación humana. Esta consideración apuntada por Lotter podría resumirse en un «imagina que...", y a partir de ahí seguir construyendo una hipótesis de cualquier tipo que podrá o no- conducirnos a una solución de la cuestión planteada o, al menos, a una nueva forma de vislumbrarla. Hay que distinguir, eso sí, entre la fantasía que va más allá de la realidad (desvinculada de ella) dando lugar al género fantástico, a la ciencia ficción y a las llamadas utopías abstractas, de la fantasía tal y como la concibe Goethe: la fantasía para la verdad de lo real. «La intención de ésta no es la creación de nuevas realidades, sino la invención de imágenes, fábulas, etc., que expresen la realidad dada en sus rasgos esenciales más verdaderamente de lo que sería posible en la simple réplica de las imágenes y los

19 Henckmann y LotTer, Diccionario de estética, Crítica, Barcelona, 1998, p. 98. 
acontecimientos presentes empíricamente» ${ }^{20}$. La fantasía, por otro lado, está a la base de ciertas utopías dirigiéndose en muchas de ellas hacia la anticipación de lo posible y como modificadora de la realidad.

El caso del pintor y escritor checo Alfred Kubin es paradigmático de esta forma de entender el arte recurriendo a la fantasía, sin, por ello, dejar de estar explorando la realidad. Alfred Kubin, pintor simbolista y precursor del Expresionismo, es conocido, sobre todo, por su obra plástica. Sus influencias van desde Goya a Bruegel, Redon, Max Klinger, Beardsley, Rops, Rembrandt, El Bosco. Ilustró libros de Hoffmann, Nerval, Poe, Bierce, Döblin, Dostoievski, Flaubert, Gogol, Meyrink, Jünger, Strindberg, Voltaire, Wells. Su obra está siendo actualmente justamente revalorizada. Sus dibujos son visiones crepusculares de una sociedad que se debatía entre el final de una etapa y el comienzo de otra; imágenes horrorizadas de la vida del hombre de su época, de sus miserias y su melancolía, de su soledad y su batalla contra lo desconocido e incomprensible; una genial antología de la neurosis y la depresión, un bestiario con los monstruos que todos llevamos dentro y que no cejan de asediarnos, a todos. Su universo es singular, como lo es el de Kafka; poblado de figuras siniestras, cuerpos mutilados y deformes, fantásticos, terribles y amenazadores en un escenario onírico imposible que, sin embargo, no deja de referirse al mundo en descomposición del hombre moderno. En este sentido sus personajes, los de carne y mucho hueso, están situados en un entorno árido, acaso desértico. No hay concesión a lo anecdótico ni al ornamento, como ocurre en la obra de muchos de sus contemporáneos. En las escenas de sus obras nos dibuja no el mejor de los mundos posibles, sino el peor. En él sus personajes se enfrentan a un poder imbatible e inaccesible, muy por encima de sus posibilidades e infinitamente superior a ellos. Kubin nos muestra un alma llena de sufrimientos, de angustia y frustraciones que se enfrenta sola ante un abismo frío y desértico como símbolo de su existencia.

Alfred Kubin cultivó, además, el relato fantástico y estuvo profundamente interesado en el mundo de los sueños. Sin embargo, la obra de mayor importancia que escribió fue La otra parte ${ }^{21}$ (1909), que es una angustiosa fábula

20 Henckmann y LoTTER, Diccionario de estética, Crítica, Barcelona, 1998, p. 98.

21 La otra parte trata del "Reino de los sueños" creado en un lugar remoto de Asia por Claus Patera, donde hallan refugio soñadores, marginados e histéricos. La capital es Perla que es una ciudad del pasado en la que el tiempo parece haberse detenido (Claus Patera siente una pro- 
sobre el poder absoluto y precursora de $E l$ proceso y $E l$ castillo, escritas años después. La otra parte fue escrita compulsivamente durante una profunda crisis creativa como dibujante, aunque el texto está acompañado de cincuenta ilustraciones. La otra parte es una obra paradigmática de la literatura utópica y su contenido alucinatorio es equiparable al que puede encontrarse en las mejores páginas de su buen amigo Franz Kafka que, por lo demás, era gran admirador de su peculiar mundo espiritual.

No escapa a la obra de Kubin una crítica a la burocracia, hipotéticamente del Imperio Austro- Húngaro, pero extrapolable a cualquier otra burocracia, que aparece después en la obra de Kafka, Musil, y otros autores. Alfred Kubin describe, con una comicidad sin precedentes, al burócrata como una especie particular dentro del homo sapiens.

«Para obtener una solicitud de audiencia necesita usted, además de sus partidas de nacimiento, bautismo y matrimonio, el certificado de escolaridad de su padre y el de vacunación de su madre. En el corredor de la izquier$\mathrm{da}$, oficina número dieciséis, tendrá que efectuar su declaración de bienes, grado de instrucción y condecoraciones obtenidas. Un certificado de buena conducta de su suegro sería también deseable, aunque no constituya requisito indispensable» ${ }^{22}$.

En realidad, en esta descripción del burócrata parece que podamos reconocer a ese funcionario que, tras una ventanilla cualquiera, ha amargado la vida a más de un usuario. En otro fragmento de La otra parte (que bien podría ser de El proceso) Kubin plasma el periplo del protagonista (que podría ser cualquiera) en un edificio de oficinas:

funda aversión contra todo lo que, en general, guarda relación con cualquier forma de progreso). La narración desarrolla la pugna entre las fuerzas del pasado y las del futuro representadas por Herkules Bell, un americano que representa otro mundo y que es la voz del progreso. Bajo la dominación de las nuevas fuerzas de la ciencia y el materialismo que Bell representa, el mundo obsoleto de los soñadores ya no puede seguir existiendo. La novela acaba con un enorme cataclismo que destruye completamente el Reino del Sueño. Patera muere, Bell escapa y el narrador (un invitado de Patera al Reino de los Sueños) vive para contar la historia. La novela, fue recibida en su tiempo como la metáfora de la propia época decadente en que vivía Kubin. Puede ser, por tanto, interpretada como una metáfora de la decadencia de la realidad austriaca en vísperas de la Primera Guerra Mundial.

22 Alfred KubIN, La otra parte, Siruela, Madrid, 1988, p. 88. 
"Comenzó entonces un interminable peregrinaje por pasillos desiertos, oficinas donde la gente se incorporaba precipitadamente al vernos entrar, como si los hubiéramos cogido por sorpresa, salas vacías y gabinetes repletos hasta el techo de actas y expedientes» ${ }^{23}$.

Tras la situación de inocente ignorancia en la que en tantas ocasiones se halla el usuario, que llega a vivir una auténtica odisea con esa ida y venida por los pasillos, oficinas y negociados de un edificio público dependiente de la administración, se encuentra esa especie, no precisamente en vías de extinción, descrita por Alfred Kubin que es el funcionario:

"Lo que me tocó vivir allí sólo les pasaba a los recién llegados. Mientras siguiera aquel camino, no obtendría nunca algo positivo. Las solicitudes más urgentes eran rechazadas por presentar errores formales de escasísima importancia. Por ese lado, uno podía tener la absoluta seguridad de que sus proyectos serían siempre desbaratados [...] Todo aquello servía, en el Estado de los sueños, para crear simple y llanamente la ilusión paródica de un cuerpo administrativo organizado. Si hubieran suprimido el Archivo las cosas no habrían marchado ni mejor ni peor. Aquellas enormes pilas de expedientes —adquiridos en todos los rincones del mundo- no tenían nada que ver con el Reino de los sueños. Para decirlo sin mayores rodeos: esa atmósfera impregnada de papeles polvorientos era necesaria para producir una variedad de bomo sapiens, que habría de aportar su nota de color a la policromía del conjunto» ${ }^{24}$.

A Alfred Kubin, el mundo de lo onírico, del sueño, le proporcionaría un importante material que fue base de sus creaciones (en parte como en Kafka). El sueño, diría, "es un mago poderoso". Pero no es el contenido de los sueños lo que a él le interesa, sino el mundo y el modo en que el sueño pasa y lo que en él se da. Por eso evoluciona de lo onírico a lo filosófico.

Como dibujante que fue, no quiero dejar pasar la oportunidad de realizar un pequeño análisis de una de sus obras más representativas: Der Eindringling (El intruso), un dibujo de 1936, en el que crea una situación dramática con tres elementos: dos personajes y una puerta. Uno de los personajes (de espalda) está dentro de la habitación $\longrightarrow$ de la casa, eso no queda claro- y trata de cerrar 
la puerta con todas sus fuerzas. El otro individuo, más grande que el primero, ocupa una posición prácticamente central en el dibujo. Es enorme, presenta un rostro terrible y amenazador, una mueca horrible, con las cejas arqueadas y la boca abierta, parece monstruoso, e intenta entrar en la habitación superando los esfuerzos del otro por dejarlo fuera. El otro, que intenta echarlo fuera, empuja la puerta desesperadamente. El esfuerzo por cerrar la puerta moviliza a todos los miembros de su cuerpo, desde las piernas hasta las manos, y su posición revela la magnitud de ese esfuerzo.

Pues bien, a primera vista encontramos que El intruso es una obra donde Kubin, como en tantas otras ocasiones, se ha expresado dándole vida a un ser producto de su fantasía que ha querido plasmar como si de un monstruo se tratara, el cual intenta entrar en la habitación o, acaso, en el domicilio de un ciudadano, con siniestros objetivos tales como el hurto o, simplemente, la invasión de la vida privada. Hasta aquí todo es bien comprensible salvo que, por supuesto, esta no es, ni mucho menos, la única ni más sustancial lectura que podemos hacer de El intruso, pues nos abordan muchas otras cuestiones de mayor calado. Por ejemplo, ¿por qué un monstruo y no un hombre de complexión fuerte, capaz, incluso más que el monstruo, de tirar la puerta sin demasiado esfuerzo? Lo cierto es que lo que Kubin nos ha dejado cifrado, tanto en este como en otros muchos dibujos, es una concepción de la alteridad, es decir, del carácter o cualidad de lo que es otro, de lo que es distinto, y el monstruo lo es. Tenemos, por tanto, un monstruo que ejerce de intruso y un hombre que trata de proteger su casa, su intimidad, su privacidad o, por qué no, de protegerse (de sí mismo) de sus fantasmas, de sus fobias, de sus miedos que, en este caso, son representadas por un monstruo. Pero las barreras físicas no tienen la resistencia suficiente para protegerse del interior de sí mismo. En ese sentido podemos comprobar que el presunto monstruo posee unas manos iguales a las del hombre que, enconadamente, le impide sin éxito la entrada al intruso. En realidad, si observamos con atención, el monstruo no intenta hacer nada de particular con sus rodillas o, al menos, con su brazo derecho. Probablemente solo con la izquierda esté realizando algún tipo de esfuerzo. No da la sensación de que esté empujando con toda la fuerza que le podríamos suponer; ni siquiera parece de complexión fuerte. En realidad su macrocefalia es el único rasgo junto con los faciales que realmente asustan. El monstruo es, simplemente, alguien diferente, algo desconocido o quizás algo conocido, que está ahí, que en cualquier momento "llamará a tu puerta" pero que, sin embargo, se prefiere evitar. La fantasía de Kubin ha creado un ser monstruoso con el que, lejos 
de evitar la realidad, nos posibilita distintas lecturas a partir de una acción plasmada en un dibujo. El hombre desde dentro intenta no dejar pasar a lo que quiera que sea que represente el intruso. Entre ellos una barrera física. Afuera la amenaza, el peligro. Dentro, una seguridad amenazada. Un maniqueísmo tan patente como peligroso. En una ulterior lectura encontramos que ni el sujeto que se encuentra en el interior tiene por qué ser inocente, ni el presunto monstruo suponer una amenaza, y si en una primera lectura puede parecerlo, a otro nivel encontramos que el otro, el monstruo, podría ser cualquiera capaz de constituir una amenaza. ¿Y quién puede suponer una amenaza? La respuesta ya está dada: el que es distinto o, sencillamente, aquel que creemos distinto. Aquella persona que tiene un comportamiento que consideramos muy particular, aquel que tiene un estatus social y económico diferente al nuestro, aquel cuyas obras difieren sustancialmente de las llevadas a cabo por cada uno de nosotros, aquel cuya cultura, raza, sexo, orientación sexual, religión, procedencia geográfica, etc., es distinta a la nuestra. En este sentido el dibujo de Alfred Kubin de 1936 cobra actualidad ostensiblemente con, simplemente, analizar la realidad que nos rodea. La de un mundo donde la seguridad, la protección y la autodefensa han venido a dejar en un segundo plano a valores muy cacareados actualmente, aunque poco practicados. Este dibujo, en efecto, resulta angustioso y aterrador; de manera análoga les debe de resultar la realidad a los cientos y miles de inmigrantes que a la búsqueda de la fantasía se encuentran con la realidad.

Si en clave de alteridad podíamos interpretar adecuadamente El intruso de Kubin, del mismo modo sería posible interpretar obras consideradas dentro del subgénero de la "novela gótica" como Frankestein o Dr Jekyll y Mr Hyde, ambas caracterizadas por su marcado tono fantástico que, sin embargo, permiten una lectura de insospechadas consecuencias realistas. Más allá del miedo irracional que infunde aquello que es distinto, lo otro, Frankestein es, además de la historia de un monstruo creado con distintas partes de seres ya fallecidos, el anhelo del hombre de erigirse en Creador, tentando a la naturaleza y eludiendo la responsabilidad de una investigación científica que escapa al control humano y que puede llegar a costar muy cara. Por otro lado, El extraño caso del Dr. Jekyll y Mr. Hyde, por ejemplo, no es solamente la conmovedora historia de un hombre que se transforma en un cruel asesino, o la lucha entre el bien y el mal. Dr Jekyll y $\mathrm{Mr}$ Hyde supone, al mismo tiempo, la condición esquizoide del hombre moderno. Ese hombre capaz de transformarse en la carretera tras la ingestión de algún narcótico, ese hombre que a lo largo de su jorna- 
da laboral presenta un bondadoso aspecto y que, sin embargo, es capaz fuera de él de convertirse en un auténtico monstruo; es esa doble vida de tantos y tantos hombres y mujeres que, tras convivir juntos durante años, una mañana, descubren que no saben nada el uno de otro. Estas obras «fantásticas» rezuman actualidad (y realidad) por los cuatro costados. Sería justo decir que la realidad no es lo que vemos habitualmente. Una vez más la literatura (y el arte, en general) muestra que está especialmente capacitado para hacer ver a través de la fantasía la realidad.

En 1915 se publica el relato largo La transformación, de Franz Kafka. En él se narra la historia de un viajante, Gregorio Samsa, que una mañana, al despertar, descubre que se ha convertido en un espantoso insecto. Como es lógico, cuando la familia descubre tal eventualidad se lleva un gran disgusto ${ }^{25}$, aunque asume el hecho e intenta vivir con él. También Gregorio acepta su situación como insólita, pero posible, acostumbrándose poco a poco a su animalidad. Más tarde, como señala Cortés, "será percibido como un impostor potencial que trata de invadir el espacio de la familia" ${ }^{26}$. Su monstruosidad le impide la convivencia en la sociedad y llega a asumir su propia desaparición, pues contraviene toda pauta socialmente aceptable.

El hecho fantástico (o sobrenatural, tanto da) que supone la transformación es un recurso de gran eficacia que crea un sin fin de expectativas hermenéuticas, amén de provocar un shock en el lector del cual ya no se repondrá en toda la obra y que, además, le hará empatizar tanto con el afectado como con su causa. En La transformación partimos de un acontecimiento sobrenatural que una vez asumido por todos va adoptando una naturalidad tal a lo largo del relato que, finalmente, da la sensación de auténtica realidad, de que es algo posible. En este sentido hay una dialéctica entre fantasía y realidad que posibilita claramente la convivencia de este binomio que, en el desenlace de la obra, resulta de un realismo inusitado, acaso insólito en muchas obras llamadas realistas y naturalistas. La consecuencia de todo ello es que el texto se presta a diversas interpretaciones, mientras que en ciertas formas de realismo la referencialidad de los medios expresivos obstruyen toda interpretación que vaya más allá de lo descrito. Para Todorov la transgresión de las leyes de la naturaleza que operan en La transformación «nos hacen cobrar una mayor con-

25 Permitaseme expresarme con esta frialdad kafkiana.

26 José Miguel G. Cortés, Orden y caos, Anagrama, Barcelona, 1997, p. 162. 
ciencia del hecho» ${ }^{27}$. Al mismo tiempo, el recurso a la fantasía produce una especie de shock en el lector capaz de neutralizarlo, de dejarlo en suspenso (parafraseando a Husserl) y, a partir de ahí, no queda más remedio que leer el relato en clave literal, "como sì lo que está pasando estuviera ocurriendo en realidad. Por esa razón hasta los detractores de la fantasía como recurso literario prosiguen su lectura de La transformación después de haber leído en sus primeras líneas la transformación (de ningún modo se trata de una metamorfosis) operada en el viajante Samsa. De este modo consigue su objetivo de empatizar con el animal y, al mismo tiempo, de que lleguemos a considerar como bestias a su familia.

Esta forma de narrar una historia partiendo de una tan prodigiosa transformación proporciona el carácter de pluridiscursividad. Así, sería lícito interpretar que, en realidad, la transformación se había producido mucho antes. Gregorio ya era un «bicho raro» en sentido figurado. Tras la transformación se convierte en un bicho raro, esta vez, literalmente. ¿Y por qué no se convierten en bichos raros los restantes, y hasta cierto punto crueles, miembros de la familia en lugar de él? Pues por una idea expresionista propia de la época y, a la vez, muy kafkiana: Kafka, como muchos expresionistas, veía en el animal un ser sobre el que se ejercían innumerables abusos, veía una pureza perdida ya por el ser humano, tal y como expresara en algunos de sus dibujos; los expresionistas (como Franz Marc) se esforzaban, en fin, por habitar el alma auténtica e incontaminada de esas criaturas infrahumanas.

En resumen, partimos de que la fantasía era un recurso literario que constituye una privilegiada puerta de entrada a la realidad al otorgarle el carácter de pluridiscursividad, es decir, capaz de interpretarla de diversos modos y haciendo de la realidad algo problemático y no algo sencillo, algo al alcance de la mano que baste con acercarse para cogerlo. Lo cierto es que no por ello la fantasía y los distintos modos de expresión no realistas (como los utilizados por las distintas vanguardias artísticas) se distancian de la realidad por el recurso o modo de expresión utilizado, sino todo lo contrario: tras haber comprobado las limitaciones de los recursos de los que se dispuso en épocas pretéritas han abordado la realidad con nuevos recursos que a la postre se han convertido en

27 T. TODOROV, Introducción a la literatura fantástica, Ed. Buenos Aires, Barcelona, 1982, p. 204. 
fecundos mecanismos de análisis sin por ello haber dejado de profundizar en la comprensión de una realidad siempre esquiva.

Como señalé al comienzo de este trabajo, hasta un detractor de Kafka como fue Georg Lukacs tuvo que rendirse ante la evidencia y comprendió el sentido de la obra del universal autor checo tras vivir una situación cercana a las descritas por Franz Kafka. Fritz Raddatz, el biógrafo de Lukács nos la recuerda:

«Tras encarcelarlo de noche en Budapest en 1956, conducirlo rápidamente en coche con las cortinillas echadas a un aeropuerto militar desconocido, llevarlo en un avión sin emblema a un país ignoto y tras llegar al fin a una villa de apariencia palaciega siruada junto a un mar rutilante, en la que viviría medio como huésped ofical ceremoniosamente agasajado, medio como presidiario, pero siempre sin saber en absoluto dónde se encontraba, Georg Lukács comentó: "Pues sí, Kafka era un realista"” ${ }^{28}$.

28 Fritz J. RadDATZ, Georg Lukács, Alianza, Madrid, 1975, p. 103. 